\title{
El regateo en el Mercado de Santa Rita: estrategias discursivas del duelo verbal ${ }^{1}$
}

\author{
Udiluz Monsalve Muñoz ${ }^{2}$ \\ Universidad de Cartagena
}

\section{Resumen}

Como hablantes, usamos la lengua para muchos propósitos comunicativos, la mayoría de ellos enmarcados dentro de nuestra cotidianidad (por ejemplo, la compra de algún producto en una tienda o plaza de mercado). Cuando no estamos de acuerdo con el precio dado por el vendedor, recurrimos de manera verbal a disputar ese precio, es decir, a regatearlo. El regateo, entonces, es un uso específico de la lengua, y aunque tiene lugar en la simple transacción de un producto, se ha convertido en una práctica comercial y cultural para quienes diariamente lo utilizan. El objetivo del presente artículo es dar cuenta de ese duelo verbal que conforma el regateo, exponiendo las estrategias discursivas que compradores y vendedores del Mercado de Santa Rita (Cartagena) utilizan para que el interlocutor acceda a sus

\section{Abstract}

We are speakers and we use language for many communicative purposes, most of them framed in our daily lives (for example: When we go to buy something in a store or marketplace). When we disagree with the price, we negotiate cost with the seller, namely, we haggle. We use specific words during bargaining for fixed prices of a product. This bargaining has become in a social and commercial practicing for people who use it daily. The objective this paper is showing the verbal dispute, words used in haggling and exposing discursive strategies from buyers to reduce costs and sellers from Santa Rita marketplace (Cartagena) to keep assigned prices.

${ }^{1}$ Este artículo se desprende de la investigación titulada Análisis de las estrategias discursivas del duelo verbal de regateo en el Mercado de Santa Rita (2011), presentada como requisito para optar al título de Profesional en Lingüística y Literatura de la Universidad de Cartagena.

2 Profesional en Línguística y Literatura de la Universidad de Cartagena. Miembro del Grupo de Investigación GIESCAH. e-mail: lulomons@gmail.com

Recibido: Marzo, 2010 - Aprobado: Junio, 2010. 
intenciones, sean éstas la rebaja de precio o tratar de mantener un costo ya asignado.

Palabras clave: regateo, estrategia discursiva, duelo verbal, comprador, vendedor.
Key words: haggling, discursive strategies, verbal dispute, buyer, seller.

\section{Introducción}

El regateo puede ser definido como "el arte de conseguir el precio que consideremos justo para un producto que estamos dispuestos a comprar" (Vizcaíno, 2008: 1). Es un arte, en cuanto el comprador necesita de tácticas y habilidades que le permitan alcanzar ese precio justo; pero ante todo, debemos considerar el regateo como una negociación. Desde esta perspectiva, podemos entenderlo como un proceso "por el que se llega a un precio en una transacción, cuando existe una negociación directa y aguda entre el comprador que empieza ofreciendo un precio que está dispuesto a subir y un vendedor que empieza demandando un precio que está dispuesto a disminuir [...]" (Seldon \& Pennance, 1975: 467)

Visto así, el regateo se convierte en un acuerdo pasivo -a pesar del carácter agudo de la negociación- en el que tanto comprador como vendedor están dispuestos a ceder al propósito del otro. Sin embargo, aunque el carácter esencial de la negociación es que "haya intereses en conflicto, pero también una zona de conveniencia mutua donde la diferencia pueda resolverse" (Ogliastri, 2001: 3), en el regateo una de las partes se sacrifica para la satisfacción de la otra, porque en realidad no interesa una zona de beneficio mutuo. Es por esto que el regateo se considera como una negociación tradicional.

Así lo deja ver Ogliastri (2001: 4) cuando afirma que existen dos tipos de negociación: una escuela tradicional y una integrativa o nueva teoría de la negociación. La primera corresponde al regateo por excelencia y se basa en la competitividad, en no ceder a las peticiones del otro, sino que ese otro acceda a las propuestas por su rival (se busca ganar el mayor beneficio, y con tal de ser el ganador, así como puede haber buen trato, puede no haberlo, y por tanto se da en la disminución del otro, o de su producto). La segunda, por el contrario, trata de evitar ese beneficio unilateral, y vela porque los dos negociadores salgan ganando: se analizan detenidamente los intereses de cada parte para llegar a un punto medio en el que la satisfacción sea mutua. 
Podemos ver entonces que la negociación tradicional es inherente al regateo y éste es esencial en la compra de los colombianos y de los cartageneros. Como explican Tabares y Arias (2008.: 1): "El regateo se ha convertido en una costumbre, hábito, estilo de vida que expresa la cotidianeidad [sic] a través de las diferentes relaciones y comportamientos que se dan entre los individuos involucrados en el ejercicio comercial". En otras palabras, es una práctica que se caracteriza no sólo por ser comercial, sino también por ser cultural. Es "una relación social" (15), ya que en ella se entrecruzan diferentes personas, y por tanto, formas de hablar y de vivir diferentes, que hallan en el Mercado de Santa Rita ${ }^{3}$ un espacio de encuentro a través de la negociación y el regateo. Así el regateo, según Tabares y Arias es:

[...] el acto de compraventa relacionado con la subasta, con ofrecer por un producto un valor determinado y discutir por la calidad y/o costo del mismo. Es averiguar varias veces, visitar varios almacenes, comparar precios y al final ofrecer lo menos en el último almacén, después de llegar a un acuerdo durante la negociación (2008: 15).

En este sentido, "no se regatea con alguien, se regatea contra alguien. El regateo es una lucha feroz por conseguir el máximo beneficio" (Vizcaíno, 2008: 11); se lucha por ser quien no se sacrifique, sino quien salga ganando. De acuerdo con esto, a nivel económico el regateo se caracteriza por ser netamente competitivo. Sherzer lo concebirá, a nivel del lenguaje, como un "duelo verbal" (2000: 528), pues esa guerra de precios sólo es posible a través del lenguaje: "El duelo verbal que resulta central para el regateo constituye una negociación de estatus y rol, así como de precio" (528). De estatus, porque por medio del duelo verbal se decide quién gana y quién pierde, y de precios, porque lo que se disputa es el costo que se acomode mejor a cada una de las partes.

\footnotetext{
3 Inaugurado en 1970 como Mercado Pedro A. Salazar, es más conocido por sus usuarios como Mercado de Santa Rita, debido al nombre del barrio en el que se encuentra ubicado. Santa Rita y los barrios aledaños están localizados en la zona norte de la ciudad de Cartagena y pertenecen a sus estratos bajos, lo cual influye, entre otras cosas, en el hábito regateador, en buscar la economía debido a la falta de recursos. El Mercado de Santa Rita es pequeño en comparación con el Mercado de Bazurto, central de abastos mayorista de Cartagena, pero es reconocido y acogido por los habitantes de los sectores cercanos por ser un lugar en el que encuentran, por un lado, todo lo relacionado con los productos de la canasta familiar, y por otro, un sitio en el que compradores y vendedores comparten anécdotas, opiniones y maneras de vivir y ver el mundo.
} 
Ahora bien, este duelo verbal se desarrolla a través de las estrategias discursivas que utilizan sus participantes, compradores y vendedores, para lograr persuadir al otro de que acceda a unos determinados propósitos. Veamos entonces en qué consisten las estrategias discursivas y cómo se ponen en juego en una situación comunicativa. Émile Benveniste considera que "la enunciación es poner a funcionar la lengua por un acto individual de utilización" (1979: 83). Dicho acto individual de uso implica la participación de un yo y un tú en la interacción discursiva, pero será el yo quien se posicione a sí mismo y al tú en dicha interacción. Patrick Charaudeau amplía este planteamiento con los "circuitos del acto de lenguaje" (citado por Escamilla, 1998). Con esta concepción busca explicar que ese posicionamiento del yo y del tú se deberá a los dos o más participantes de la interacción. Es decir, no es unilateral, sino bilateral, y por tanto, dará cuenta en su teoría del desdoblamiento del yo y el tú en la conversación.

Vale aclarar que son dos circuitos: uno externo y uno interno. El externo hace alusión a los seres reales implicados en la conversación: éstos son, un sujeto comunicante o yo comunicante y un sujeto interpretante o tú interpretante; y el circuito interno se refiere a los sujetos discursivos, los cuales, a su vez, son sujeto enunciante o yo enunciante y sujeto destinatario o tú interpretante. El circuito interno es el "circuito de configuración discursiva" (Escamilla, 1998: 33 ), pues conforma las idealizaciones discursivas que hace el yo enunciante de su sujeto destinatario. El sujeto enunciante (Yoe) es quien expresa la intencionalidad del sujeto comunicante que produce el discurso, y el sujeto destinatario "es el interlocutor fabricado por el comunicante (Yoc) como destinatario ideal y adecuado para su acto de enunciación" (34).

Circuito externo: Sujeto comunicante $\Longleftrightarrow$ Sujeto interpretante (Yo comunicante) (Tú interpretante) $\begin{aligned} \text { Circuito interno: Sujeto enunciante } & \Longleftrightarrow \text { Sujeto destinatario } \\ \text { (Yo enunciante) } & \text { (Tú interpretante) }\end{aligned}$

"Circuito del acto del lenguaje", propuesto por Charaudeau (citado por Escamilla, 1998: 33)

Con base en lo anterior, podemos entender por estrategia discursiva un recurso por medio del cual: 
[...] el sujeto comunicante concibe, organiza y pone en ejecución sus intenciones con el fin de producir ciertos efectos de convicción, de seducción en el sujeto interpretante y llevarlo a que se identifique -conscientemente o no- con el destinatario que ese comunicante se ha construido mentalmente (Escamilla, 1998: 39).

De acuerdo con la situación, las circunstancias en que surja y el contrato discursivo que establezcan, los participantes harán uso de determinadas estrategias. Cuando hablamos de contrato discursivo, nos referimos al reconocimiento, por parte de los usuarios de una lengua, de ciertas representaciones discursivas de las prácticas sociales del grupo al cual pertenecen dichos usuarios (Escamilla, 1998: 38). Por ejemplo, la interacción que se establece entre un comprador y un vendedor está mediada por llevar a cabo un contrato discursivo: la compra y venta de un producto específico.

El contrato discursivo de compra-venta que se establece al momento que un cliente llega a una colmena de abastos, por ejemplo, y quiere comprar algo, es reconocido por toda la población (cartagenera, en este caso). Sin embargo, cuando el comprador, como sujeto enunciante, exige la rebaja de precio de un producto, está estableciendo otro contrato: el contrato discursivo del regateo. El sujeto interpretante reconoce así este contrato y la conversación girará en torno al acuerdo de precios. Si el sujeto enunciante logra que el sujeto interpretante acceda a la rebaja de precio de un determinado producto, para lo cual hizo uso de diversas estrategias discursivas, quiere decir que la idealización discursiva -del sujeto enunciante sobre un sujeto destinatario que respondía a ese propósito de rebaja de precio- se ha cumplido a cabalidad.

\section{Estrategias discursivas usadas por los compradores}

En una situación de compraventa, lo más importante para los participantes, en el caso del comprador, es obtener la rebaja de precio del producto que desea adquirir; y para el vendedor, dar razones al comprador de porqué no puede vender el producto al costo que aquél exige y, a la vez, persuadirlo de que lleve el artículo. Más que la aparente disputa o "pelea" que tiene lugar en el regateo, ésta no corresponde más que a una serie de estrategias discursivas que los mismos usan para conseguir sus propósitos. Son sólo acciones de un duelo verbal caracterizado por la familiaridad entre los participantes. 
Vale aclarar que las estrategias discursivas estudiadas por Escamilla $(1998)^{4}$ no serán analizadas en relación con las estrategias de regateo, pues aunque no se descarta la existencia de cierta conexión entre ellas, consideramos que (conforme a la revisión del corpus) las estrategias esbozadas por este autor no son puestas en práctica por los compradores y vendedores del Mercado de Santa Rita. Pensamos, más bien, que los duelos de regateo en esta plaza se desarrollan con su propio "juego" de estrategias.

A pesar de ello, resulta evidente que tanto las estrategias discursivas propuestas por Escamilla, como las usadas en el regateo, coinciden en un propósito: la búsqueda de un sujeto enunciante por lograr que un tú destinatario ${ }^{5}$ acceda a sus intenciones. Así lo explica Escamilla (1998):

[...] la combinación de las estrategias discursivas es una prueba de la importancia de la dimensión pragmática del lenguaje, consistente en convencer y persuadir al sujeto destinatario de aquello que uno dice con el fin de incitarlo a la acción o hacer que asuma una determinada actitud (50).

De la misma forma sucede en las situaciones de regateo, cuyo objetivo principal es lograr que el otro, el sujeto destinatario, acceda a los propósitos de un yo enunciante. En esta medida, en el regateo

${ }^{4}$ Escamilla (1998) enfatiza su estudio en las estrategias discursivas de la mentira, la ironía, el secreto, la demagogia y la provocación. No descartamos, sin embargo, el hecho de que la mentira pueda presentarse en algunas de las estrategias discursivas de regateo, pues lo más importante para el comprador o el vendedor es alcanzar el beneficio propuesto, aunque muchas de las afirmaciones realizadas no sean veraces. Por ejemplo, cuando un comprador desvaloriza un producto, puede hacerlo señalando defectos que, tal vez, el producto realmente no tiene; o en el caso del vendedor, lo más probable es que al aseverar que tiene los mejores costos de toda la plaza, esto sea falaz.

${ }^{5}$ Este "circuito de configuración discursiva", caracterizado por el desdoblamiento de cuatro protagonistas (sujeto comunicante-sujeto interpretante, sujeto enunciante-sujeto destinatario), es una propuesta que refuta el modelo tradicional de la comunicación, emisor-receptor, en el cual sólo uno de los participantes es dueño de la información y por tanto tiene la capacidad de transmitirla, mientras que el otro sólo es un participante pasivo. Vista de esta forma, la comunicación es transparente y clara. Por el contrario, en el planteamiento de Charaudeau (citado por Escamilla, 1998), la comunicación se basa en un "acto interenunciativo", en el que no hay un emisor y un receptor, sino sujetos con intencionalidades diversas, que producen e interpretan enunciados de acuerdo a dichas intenciones. En esta medida, la comunicación también responde a las prácticas y convenciones culturales que regulan la forma en la que los enunciados sean comprendidos. 
no se negocian beneficios comunes, sino individuales. El regateo es un duelo, una "pelea" de estrategias que permiten, a quien las use creativamente, ser el vencedor y alcanzar un beneficio particular. Es decir, si en este duelo se llega a un acuerdo, éste no será satisfactorio para las dos partes involucradas. En lo que concierne a la parte del comprador, en algunas situaciones es éste quien propone el contrato discursivo de regateo desde el inicio del diálogo; en otras, el comprador comienza el duelo después de que le ha preguntado al vendedor por el producto, ya sea por su precio o simplemente para observarlo, y en reacción a que el precio dado le parezca muy elevado o a que el artículo no es de la calidad que lo esperaba, comienza a regatear.

No podemos decir que en el desarrollo del diálogo, el comprador cuente con unas estrategias pre-establecidas de inicio del duelo verbal (regateo), otras estrategias de despliegue y otras de cierre. En tanto parte de la dimensión pragmática del lenguaje, las estrategias discursivas no son prefijadas: éstas se suceden en la interacción, de acuerdo con los propósitos, las necesidades y los intereses de los participantes. No obstante, sí podemos afirmar que existen unas estrategias que insinúan la petición de rebaja y otras que la exigen directamente. En este sentido, una "intervención de inicio" (Briz, 1998: 53) de un diálogo, que inmediatamente comience el duelo de regateo, puede hacer uso de una estrategia que sugiera la rebaja o de una estrategia que la reclame al instante. De igual forma, una "intervención de reacción", después de que el comprador ha escuchado el precio del producto o lo ha observado, puede usar una estrategia que insinúe la rebaja o que la exija ${ }^{6}$.

\footnotetext{
${ }^{6}$ El regateo es un duelo verbal que se desarrolla, principalmente, a través de una conversación. Pero esta conversación, por su tono informal, por la relación de iguales entre sus participantes, y sobre todo, por su espontaneidad (es decir, la planificación de lo que se va a decir ocurre sobre la marcha), puede ser considerada una conversación coloquial (Briz, 1998: 41). Dado su carácter conversacional, las situaciones de regateo fueron analizadas con base en los conceptos que dan cuenta de la estructura de una conversación. Esos son: los turnos, los cuales dan un orden a la interacción y permiten que cada participante tenga un espacio para expresarse. En otras palabras, el turno: "es un hueco estructural rellenado con emisiones informativas que son reconocidas por los interlocutores mediante su atención manifiesta y simultánea" (Briz, 1998: 52), y esas "emisiones" que ocupan dicho espacio son las "intervenciones" (53). Si los otros participantes le prestan atención a una determinada intervención, y por tanto, ésta es significativa dentro del diálogo, la intervención será considerada un turno. Si sucede lo contrario, es decir, si no hay una atención manifiesta por parte de los otros interlocutores, la intervención no será reconocida como tal. Cabe agregar que hay dos tipos de intervenciones: una intervención de inicio que provoca una intervención de reacción. La sucesión de estas dos intervenciones da lugar a un "intercambio" (Briz, 1998: 54), y la unión de varios intercambios constituye el "diálogo o la interacción” (54).
} 
De acuerdo con lo planteado, hemos podido establecer dos categorías que abarcan las estrategias discursivas de regateo usadas por los compradores: las estrategias discursivas de insinuación, por medio de las cuales el comprador da a entender al vendedor que está solicitando una rebaja de precio, pero no lo expresa directamente. $Y$ las estrategias discursivas de reclamación, con las que el comprador expresa directamente al vendedor la solicitud de rebaja de precio, hasta el punto de exigirla. Veamos un ejemplo de ello en el siguiente cuadro:

\begin{tabular}{|c|c|}
\hline $\begin{array}{c}\text { Estrategias discursivas de } \\
\text { insinuación }\end{array}$ & Ejemplo \\
\hline $\begin{array}{l}\text { Desvalorización del producto: el compra- } \\
\text { dor le hace ver o le hace creer al vende- } \\
\text { dor que el producto es de mala calidad y } \\
\text { por el estado en el que se encuentra no } \\
\text { justifica el pago de un precio alto. Esta } \\
\text { estrategia tiene dos variantes: la compa- } \\
\text { ración y la señalación de defectos }\end{array}$ & $\begin{array}{l}\text { Comparación: } \\
\text { C: ¿A cómo son los limones?, jje! ¡Los } \\
\text { cocos! (risas). Esos cocos parecen } \\
\text { unos limones } \\
\text { Señalación de defectos: } \\
\text { C: ¿El aguacate a cómo? } \\
\text { V: A } 1.000 \text { y a } 1.500 \\
\text { C: Pero ese tiene la punta fea [...] y } \\
\text { ese, ese tiene un golpe }\end{array}$ \\
\hline $\begin{array}{l}\text { Afirmación del alza o baja del precio del } \\
\text { producto: el comprador afirma que el } \\
\text { producto está barato para que el vende- } \\
\text { dor confirme su aseveración y venda el } \\
\text { producto a un bajo precio. Si se afirma lo } \\
\text { contrario, que el producto ha subido de } \\
\text { precio, el vendedor, con tal de despachar } \\
\text { el artículo, se opondrá a esta afirmación } \\
\text { y bajará su precio. }\end{array}$ & $\begin{array}{l}\text { Afirmación de la baja del precio: } \\
\text { C: ¿A cómo tienes el aguacate? Ya eso } \\
\text { bajó } \\
\text { Afirmación del alza del precio: } \\
\text { C: El mango está caro }\end{array}$ \\
\hline $\begin{array}{l}\text { Amenaza de no realización de la compra: } \\
\text { si el comprador no compra, no hay ga- } \\
\text { nancia ni para él ni para el vendedor. El } \\
\text { primero, entonces, se aprovecha de esta } \\
\text { situación para intimidar al segundo y } \\
\text { obtener la rebaja. Es la forma en la que el } \\
\text { comprador se posiciona como tal y hace } \\
\text { valer su rol. }\end{array}$ & $\begin{array}{l}\text { (La compradora regatea el precio de } \\
\text { unos cocos) } \\
\text { C: ¡Te dije que } 1.500 \text { ! } \\
\text { V: ¡Tú qué crees, que eres la que } \\
\text { mandas aquí! } \\
\text { C: iQué ná! Échalos ahí (la señora } \\
\text { abre una bolsa). Estás buscando } \\
\text { que no compre ná' }\end{array}$ \\
\hline
\end{tabular}

${ }^{7}$ Entendiéndose la señalación, desde la perspectiva de Peirce, como el acto de indicar o mostrar los defectos del producto -mas no como el acto de hacer señales con signos índice-: "El índice es el signo inmediato, casi natural, que representa de modo directo, por ejemplo un grito en la calle significa al que lo emitió, las nubes representan la lluvia, el humo al fuego, etc." (Beuchot, 2004: 138). 
Compromiso de dar el dinero restante: si el vendedor está muy reacio a disminuir el precio de un artículo, el comprador puede hacerle creer que le pagará posteriormente lo que debe. De esta forma, la petición de la rebaja es disimulada.
(La compradora regatea el precio de unos maíces)

C: Ignacio, ¿no me das 2 por 500 aaa?, ¿no me das dos por 500 ?

$\mathrm{V}$ : Nada, es que son 600, porque después no gano

C: Bueno, coge los 500. Ahora que vuelva a comprar el arroz te doy los 100

\begin{tabular}{|c|c|}
\hline $\begin{array}{l}\text { Estrategias discursivas de } \\
\text { reclamación }\end{array}$ & Ejemplo \\
\hline $\begin{array}{l}\text { Afirmación de la cantidad de dinero que } \\
\text { posee: más que expresar el dinero con } \\
\text { que cuenta el comprador, es una forma } \\
\text { de fijar el precio, sin darle posibilidad } \\
\text { al vendedor de objetar la función que el } \\
\text { comprador se ha atribuido: la de estable- } \\
\text { cer el precio de los artículos. }\end{array}$ & $\begin{array}{l}\text { C: ¿A cómo son los limones?, jje! ¡Los } \\
\text { cocos! (risas). Esos cocos parecen } \\
\text { unos limones } \\
\text { V: Hay a ocho, a mil y a mil } \\
\text { quinientos } \\
\text { C: (La señora observa los de } 800 \\
\text { pesos) Dame dos. Tengo } \mathbf{1 . 5 0 0}\end{array}$ \\
\hline $\begin{array}{l}\text { Afirmación de compras anteriores con el } \\
\text { precio de rebaja: el comprador asegura } \\
\text { que, como fiel cliente del establecimiento, } \\
\text { en otras ocasiones ha comprado allí el } \\
\text { producto a un precio más barato. De esta } \\
\text { forma, exige que el vendedor le venda el } \\
\text { producto a dicho precio, en respuesta a } \\
\text { su fidelidad. }\end{array}$ & $\begin{array}{l}\text { (El comprador regatea el precio de } \\
\text { un salchichón) } \\
\text { C: ¡Tres mil seis! ¡Tres mil seis! } \\
\text { V: Tres mil setecientos vale } \\
\text { C: Tres mil seis pa' comprártelo ya, } \\
\text { siempre que vengo lo compro a } \\
\text { tres mil seis }\end{array}$ \\
\hline $\begin{array}{l}\text { Referencias de otros lugares de compra: } \\
\text { con esta estrategia el comprador le hace } \\
\text { ver al vendedor que sus productos son } \\
\text { muy caros, en comparación al de otros } \\
\text { lugares de los que también es cliente. Así } \\
\text { hace que el vendedor quiera igualar sus } \\
\text { precios con los del lugar referenciado. }\end{array}$ & $\begin{array}{l}\text { V: Sí, a } 200 \text {, a } 200 \\
\text { C: Erda, Álvaro, a } 200 \text { esos tomates } \\
\text { tan feos y esos tomates no bajan. } \\
\text { Voy al mercado y los consigo más } \\
\text { baratos }\end{array}$ \\
\hline $\begin{array}{l}\text { Muestra de insatisfacción por cantidad: } \\
\text { cuando el comprador siente que no ha } \\
\text { recibido la cantidad apropiada del pro- } \\
\text { ducto por el cual ha pagado lo suficiente, } \\
\text { exige al vendedor la medida justa. Con } \\
\text { esta estrategia no sólo se regatea el pre- } \\
\text { cio, sino también la cantidad de producto } \\
\text { que se recibe al haber pagado ese precio. }\end{array}$ & $\begin{array}{l}\text { C: Véndeme } 500 \text { pesos de cebollín } \\
\text { (el vendedor coge la verdura y quita } \\
\text { algunas partes) No, pero eso no, no } \\
\text { le quites eso, véndeme } 500 \text { pesos } \\
\text { de cebollín bien despacha'o }\end{array}$ \\
\hline
\end{tabular}




\begin{abstract}
Lo más por menos: el comprador exige al vendedor más unidades del producto, a un menor precio. El primero es consciente de que no está pagando el precio correspondiente, pero el vendedor, con tal de ganar algo, accede a esa petición.
\end{abstract}

C: ¿Estos 4 plátanos?

V: Son mil

C: ¡¿qué mil?!, ¿no son a 200 ?

V: No, son mil

C: Dame los cinco por mil
Pregunta inmediata por el precio de rebaja: al comprador no le interesa saber el precio real del producto, sino el precio de rebaja que le va a dar el vendedor, por eso hace la pregunta por el precio más barato, sin rodeos.
C: ¿Y esa papaya a cómo me la va a dejar?

V: A 1500

C: ¿Qué?

V: 1500
Petición directa del precio de rebaja: Si el comprador no está de acuerdo con el precio dado por el vendedor, puede exigir de forma inmediata un precio más bajo, aunque para el vendedor esto signifique despachar menor cantidad del producto.
C: Los tomates de árbol

V: ¿Medio kilo? (lo pesa)

C: ¿Cuánto hay ahí?

V: 1200

C: ¿Qué? Dame mil

\section{Estrategias discursivas usadas por los vendedores}

En lo que respecta al vendedor, su papel fundamental en el duelo verbal de regateo es convencer al comprador de las razones que no le permiten vender los productos al precio que el comprador sugiere o exige. Para el vendedor, sin embargo, también es importante la venta, y por esto debe estar preparado al mismo tiempo para negociar con el cliente y tratar de persuadirlo. De acuerdo con esto, podemos decir que no es sólo el comprador quien inicia el regateo. El vendedor también puede comenzar este duelo verbal proponiendo sus productos al cliente a través de diversas estrategias.

Pero en razón de que en la mayoría de los casos analizados el vendedor entra al duelo porque el comprador es quien lo inicia, hemos organizado las estrategias discursivas de los vendedores teniendo en cuenta, en primer lugar, su actitud de resistencia frente al afán del comprador de adquirir los productos a precios más bajos, $\mathrm{y}$ atendiendo, en segundo lugar, a que el objetivo de vender haga que los comerciantes usen, sobre todo, estrategias de promoción de sus productos y de su establecimiento. Éstas constituyen también una forma de oposición a la petición de rebaja del comprador.

En este orden de ideas, encontramos dos categorías que reúnen las estrategias discursivas de los vendedores: las estrategias discursivas de oposición, a través de las cuales el vendedor rechaza la solicitud 
de rebaja de precio del comprador, sea ésta una solicitud insinuada o reclamada, y justifica la razón de no aceptar dicha petición. Y las estrategias discursivas de venta: el vendedor usa éstas, por un lado, para oponerse a la solicitud de rebaja, y por otro, para promocionar la calidad de sus productos y lograr que el comprador los adquiera.

\begin{tabular}{|c|c|}
\hline Estrategias discursivas de oposición & Ejemplo \\
\hline $\begin{array}{l}\text { Posicionamiento del vendedor como com- } \\
\text { prador: muchas veces acceder a precios } \\
\text { tan bajos perjudica al vendedor, pues su } \\
\text { meta es ganar un poco más del costo que } \\
\text { pagó en la sucursal mayorista. Por esto, } \\
\text { el vendedor expone como razón su rol } \\
\text { como comprador, para que los clientes } \\
\text { se percaten de que si vende los produc- } \\
\text { tos al mismo precio en el que los compró } \\
\text { no sale beneficiado. }\end{array}$ & $\begin{array}{l}\text { C: Los tomates de árbol } \\
\text { V: ¿Medio kilo? (lo pesa) } \\
\text { C: ¿Cuánto hay ahí? } \\
\text { V: } 1.200 \\
\text { C: ¿Qué? Dame mil } \\
\text { V: Vamos a sacarle pa' que sean mil } \\
\text { (saca un tomate) } \\
\text { C: Vas a sacar el más grande } \\
\text { V: Si el tomate me sale a } 200\end{array}$ \\
\hline $\begin{array}{l}\text { Posicionamiento del vendedor como due- } \\
\text { ño del establecimiento: con esta estrategia } \\
\text { el vendedor no permite que el comprador } \\
\text { se atribuya la función de dar precio a los } \\
\text { productos, pues dicha función sólo le co- } \\
\text { rresponde a él como propietario del pues- } \\
\text { to. Pero, como ya hemos mencionado, en } \\
\text { el regateo la relación es funcionalmente } \\
\text { igual, por lo cual para el comprador el } \\
\text { vendedor no representa la autoridad que } \\
\text { afirma ser. }\end{array}$ & $\begin{array}{l}\text { C: ¡Te dije que } 1500 \text { ! } \\
\text { V: ¡Tú qué crees, que eres la que } \\
\text { mandas aquí! } \\
\text { C: ¡Qué ná! Échalos ahí (la señora } \\
\text { abre una bolsa). Estás buscando que } \\
\text { no compre ná'. }\end{array}$ \\
\hline $\begin{array}{l}\text { Rebaja de precio antes de que el compra- } \\
\text { dor la exija: el vendedor puede antici- } \\
\text { parse a que el cliente le pida la rebaja. } \\
\text { De hecho, al usar esta estrategia impide } \\
\text { que el comprador dé inicio al duelo de } \\
\text { regateo, porque asume que ya dio un } \\
\text { precio razonable que el comprador no } \\
\text { refutará. Cabe aclarar que, aunque no es } \\
\text { una estrategia usada como reacción a la } \\
\text { solicitud de rebaja del cliente, la consi- } \\
\text { deramos como una estrategia de oposi- } \\
\text { ción, pues lo que busca el vendedor es } \\
\text { que el comprador no pida la rebaja, y en } \\
\text { este sentido es una forma de resistirse a } \\
\text { la petición y al duelo mismo. }\end{array}$ & $\begin{array}{l}\text { C: ¿A cómo la maracuyá? } \\
\text { V: } 3.200 \\
\text { C: ¿mil? } \\
\text { V. ¡3.200! (alza la voz). } \mathbf{3 . 2 0 0} \text { para } \\
\text { usted. }\end{array}$ \\
\hline
\end{tabular}




\begin{tabular}{|c|c|}
\hline Estrategias discursivas de venta & Ejemplo \\
\hline $\begin{array}{l}\text { Posicionamiento de ser el vendedor con } \\
\text { los mejores precios: el vendedor se adula } \\
\text { y le da a entender al comprador que, en } \\
\text { comparación al resto de los vendedores, } \\
\text { en su establecimiento puede conseguir } \\
\text { buenos precios, sin tener que pedir la } \\
\text { reducción de los costos de los artículos. }\end{array}$ & $\begin{array}{l}\text { C: ¿A cómo tiene la mano de } \\
\text { plátano? } \\
\text { V: Para ti a } 1500 \text {, es el más barato } \\
\text { que hay } \\
\text { C: ¡Ira, que el más barato! } \\
\text { V: El más barato, míralo, está bueno. }\end{array}$ \\
\hline $\begin{array}{l}\text { Valorización del producto: además de ser } \\
\text { una estrategia que busca contradecir la } \\
\text { desvalorización del producto usada por } \\
\text { los compradores, también tiene como } \\
\text { finalidad persuadir al comprador de que } \\
\text { los productos que vende son de buena } \\
\text { calidad y ameritan pagar el precio que el } \\
\text { vendedor indique. }\end{array}$ & $\begin{array}{l}\text { C: ¿A cómo el aguacate? } \\
\text { V: A mil } \\
\text { C: ¿Todo a mil? } \\
\text { V: Todo a mil, mi reina. Hasta la } \\
\text { concha, mira, está bonita }\end{array}$ \\
\hline $\begin{array}{l}\text { Afirmación del bajo costo de los produc- } \\
\text { tos: es unas de las estrategias más re- } \\
\text { currentes entre los vendedores, pues } \\
\text { frente a cualquier táctica usada por los } \\
\text { compradores, los primeros pueden afir- } \\
\text { mar simplemente que sus productos es- } \\
\text { tán baratos, y los segundos, con escuchar } \\
\text { tal aseveración, pueden convencerse de } \\
\text { comprar el artículo con el precio estable- } \\
\text { cido por el vendedor. }\end{array}$ & $\begin{array}{l}\text { C: ¿Y esa papaya a cómo me la va a } \\
\text { dejar? } \\
\text { V: A } 1.500 \\
\text { C: ¿Qué? } \\
\text { V: } 1.500 \\
\text { C: Está cara } \\
\text { V: Nombe está barata, está en } \\
\text { promoción } \\
\text { C: Está cara. (Después de pensarlo) } \\
\text { Dámela pues. }\end{array}$ \\
\hline
\end{tabular}

\section{Estrategias discursivas de apoyo}

Además de las estrategias expuestas, los compradores y vendedores del Mercado de Santa Rita se valen de las que hemos denominado estrategias discursivas de apoyo, las cuales son tácticas conversacionales usadas para respaldar las estrategias ya mencionadas y también contribuyen a rebatir las intenciones y propósitos del interlocutor. 


\begin{tabular}{|c|c|}
\hline Estrategias discursivas de apoyo & Ejemplo \\
\hline $\begin{array}{l}\text { Reacción en construcción eco: las cons- } \\
\text { trucciones eco (Briz, 1998: 73) son repe- } \\
\text { ticiones que se realizan inmediatamente } \\
\text { después de un enunciado y pueden darse } \\
\text { de dos maneras: el mismo hablante repite } \\
\text { su intervención, o un interlocutor repite } \\
\text { lo dicho por otro participante. Los parti- } \\
\text { cipantes de un diálogo pueden, por ejem- } \\
\text { plo, hacer eco en forma exclamativa de un } \\
\text { precio con el que no están de acuerdo. }\end{array}$ & $\begin{array}{l}\text { El hablante repite su intervención } \\
\text { C: ¿A cómo tienes el aguacate? Ya } \\
\text { eso bajó } \\
\text { V: Sí, ya bajó, a } 2.500 \text { y a } 1.500 \text { (la } \\
\text { compradora lo observa fijamente } \\
\text { demostrando no creerle). Sii, ya } \\
\text { bajó hace raato. Pero, mira, están } \\
\text { maduritos, esto es un súper agua- } \\
\text { cate, un súper aguacate. } \\
\text { El hablante repite lo dicho por otro } \\
\text { interlocutor } \\
\text { C: ¿A cómo estos tres plátanos? } \\
\text { (coge tres) } \\
\text { V: Dame mil ya } \\
\text { C: ¡qué mil! } \\
\text { V: ¡Ay si son a } 400 !\end{array}$ \\
\hline $\begin{array}{l}\text { Repetición: “[...] es un recurso de cohe- } \\
\text { sión, una marca de continuidad, a partir } \\
\text { del cual se logra recuperar el hilo de la } \\
\text { comunicación tras una interrupción mo- } \\
\text { mentánea del mismo" (Briz, 1998: 71). La } \\
\text { repetición constituye una estrategia dis- } \\
\text { cursiva que busca, además, hacer énfasis } \\
\text { en algo que ya se ha dicho. }\end{array}$ & $\begin{array}{l}\text { C: Échame } 200 \text { más de ají, pero } \\
\text { echa bastante, estás echando muy } \\
\text { poquito. } \\
\text { V. Ay, si son } 200 \\
\text { C: No, echa bastante }\end{array}$ \\
\hline $\begin{array}{l}\text { Silencio: expresa resignación cuando se } \\
\text { resulta perdedor de un duelo, pero en } \\
\text { otros casos manifiesta rechazo y escepti- } \\
\text { cismo ante una propuesta. }\end{array}$ & $\begin{array}{l}\text { C: Tienes zanahoria } \\
\text { V: Sí. mira, a } 200 \\
\text { (El comprador permanece en silen- } \\
\text { cio) } \\
\text { C: ¿Y cebolla? } \\
\text { V: Pero aquí tengo a } 100 \text {, baratico } \\
\text { C: Bueno, dame la de } 100\end{array}$ \\
\hline $\begin{array}{l}\text { Uso del diminutivo: es un recurso de ate- } \\
\text { nuación (Briz, 1998: 144) que permite a } \\
\text { los participantes aminorar ciertas carac- } \\
\text { terísticas del producto por el cual se dis- } \\
\text { cute en el duelo de regateo, o reducir el } \\
\text { tamaño del producto mismo. Constituye } \\
\text { una estrategia de atenuación cuando los } \\
\text { interlocutores, por medio de ésta, quieren } \\
\text { llevar a cabo alguna intención dentro del } \\
\text { diálogo. }\end{array}$ & \multirow{2}{*}{$\begin{array}{l}\text { C: ¿A cómo son las mazorquitas? } \\
\text { V: A } 300 \text { pesitos } \\
\text { C: Ignacio, ¿no me das } 2 \text { por } 500 \\
\text { aaa?, ¿no me das dos por } 500 \text { ? } \\
\text { V: Nada, es que son } 600, \text { porque } \\
\text { después no gano } \\
\text { C: Bueno, coge los } 500 \text {. Ahora que } \\
\text { vuelva a comprar el arroz te doy los } \\
100\end{array}$} \\
\hline $\begin{array}{l}\text { Alargamiento vocálico: es un recurso in- } \\
\text { tensificador (Briz, 1998, p. 124), a través } \\
\text { del cual los participantes expresan gran } \\
\text { cantidad de cualquier producto o carac- } \\
\text { terística del mismo; en algunos casos, ex- } \\
\text { presa insistencia. }\end{array}$ & \\
\hline
\end{tabular}




\begin{tabular}{|c|c|}
\hline $\begin{array}{l}\text { Prefijo intensificador (Briz, 1998: 117): } \\
\text { como su nombre lo indica, es un recurso } \\
\text { de intensificación que aumenta la calidad } \\
\text { de un producto. Con su uso, el vendedor } \\
\text { trata de que el comprador se percate de } \\
\text { que no está adquiriendo un producto } \\
\text { cualquiera, sino el mejor. }\end{array}$ & $\begin{array}{l}\text { C: ¿A cómo tienes el aguacate? Ya } \\
\text { eso bajó } \\
\text { V: Sí, ya bajó, a } 2.500 \text { y a } 1.500 \text { (la } \\
\text { compradora lo observa fijamente } \\
\text { demostrando no creerle). Sii, ya } \\
\text { bajó hace raato. Pero, mira, están } \\
\text { maduritos, esto es un súper } \\
\text { aguacate, un súper aguacate. }\end{array}$ \\
\hline $\begin{array}{l}\text { Hiperbolización: con esta estrategia se } \\
\text { exageran características de un producto } \\
\text { para demostrar que el precio dado a éste } \\
\text { es excesivo, o también se exageran situa- } \\
\text { ciones, opiniones, que incluso llegan a la } \\
\text { burla. }\end{array}$ & $\begin{array}{l}\text { V: Dame } 500 \text { pesos por este ñame- } \\
\text { cito } \\
\text { C: Eso no habla. }\end{array}$ \\
\hline
\end{tabular}

\section{Las estrategias discursivas en duelo}

A continuación, veamos cómo las estrategias discursivas de regateo son puestas en práctica por los compradores y vendedores del Mercado de Santa Rita en algunos de los diálogos recolectados. Como duelo verbal, el regateo se caracteriza por ser un enfrentamiento en el que tanto compradores como vendedores interactúan empleando las estrategias discursivas. En esta interacción el regateo es un diálogo, cuya estructura varía de acuerdo con la situación comunicativa en la que tenga lugar, es decir, conforme a sus participantes, al establecimiento en el que se da la interacción, al producto que se regatea, etc.

De manera que, en su mayoría, las intervenciones de inicio serán una pregunta por el costo de un determinado producto. Pero existen algunas excepciones. Notaremosqueno hayun saludoo una despedida; lo más importante es la negociación o el duelo. Éste se desarrollará a través de una conversación rápida en la que las intervenciones no son extensas, debido a que se entiende que el comprador necesita hacer otras compras y el vendedor necesita seguir atendiendo a otros clientes. Cabe aclarar que el carácter precipitado del diálogo no implica formalidad, por el contrario, las interacciones transcurren con una coloquialidad que se hace presente en elementos como la espontaneidad, la relación de iguales, y sobre todo, la proximidad entre los participantes (Briz, 1998: 41).

\section{a. "Esos cocos parecen unos limones"}

En la siguiente situación una compradora observa los productos que el vendedor ha colocado por fuera de las barreras de la región 
(Goffman, 2004: 254) ${ }^{8}$. La intervención de inicio de la compradora es la pregunta por el costo de unos limones. Pero la pregunta da un giro burlesco que termina con la corrección de lo dicho. En realidad, la compradora preguntaba por cocos. El cotejo que hace la interlocutora de un producto con otro más pequeño es una de las formas de la estrategia discursiva de desvalorización del producto9: la comparación. Ésta se da en el diálogo de forma hiperbólica, pues se disminuye exageradamente el tamaño del artículo.

\author{
C: ¿A cómo son los limones?, ¡je! ¡Los cocos! (risas). \\ Esos cocos parecen unos limones \\ $V$ : Hay a ocho, a mil y a mil quinientos \\ C: (La señora observa los de 800 pesos) Dame dos. \\ Tengo 1.500 \\ (El vendedor le da el vuelto de un billete de $\$ 2.000$, es \\ decir: \$400) \\ C: ¡Te dije que 1500 ! \\ $V:$ ¿¿Tú qué crees, que eres la que mandas aquí?! \\ C: ¡Qué ná'! échalos ahí (la señora abre una bolsa). Estás \\ buscando que no compre ná'
}

\footnotetext{
${ }^{8}$ Goffman (2004) considera que las relaciones sociales pueden ser vistas desde una perspectiva dramatúrgica, puesto que cuando un individuo interactúa con otros es como si estuviéramos en presencia de una representación teatral en la que hay unos actores desempeñando ciertos papeles, en un escenario y con unos elementos contextuales específicos. En esta medida, el regateo, como un duelo verbal que es (ante todo, una interacción), puede entenderse como una representación, cuyos actores son las personas que asumen los roles de comprador y vendedor. El Mercado de Santa Rita es el "establecimiento social" (Goffman, 2004: 254) destinado a la actividad de compra-venta y en el que tienen lugar estas actuaciones. Cada local comercial del mercado es, a la vez, un establecimiento social o "región" (117), dividido por paredes o barreras. Como toda representación, el regateo cuenta con su "fachada" (Goffman, 2004: 34), la cual está conformada, 1) por el medio o la utilería, es decir, el trasfondo escénico y los elementos que en él se utilizan -en el mercado en cuestión, encontramos los productos y ubicación de los mismos en estantes, neveras o cajas dentro del establecimiento comercial de forma visible al comprador, así como otros elementos tales como bolsas, básculas y el dinero-, y 2) por la fachada, que alude a las características de la persona actuante, esto es, su aspecto físico y cómo hace uso de su cuerpo en la interacción.

${ }^{9}$ No concebimos este concepto desde el ámbito de la economía, que entiende la desvalorización como la "[d]ismunución "del valor de una moneda fiduciaria con relación al oro [...]” (Martínez Cortiña, 1980: 401). Tampoco puede confundirse con el término "devaluación", que alude a la "[r]educción del valor de la moneda nacional en términos de las monedas extranjeras" (Seldon \& Pennance, 1975: 195). Como estrategia discursiva, la desvalorización implica una muestra de menosprecio por el producto del vendedor, es decir, literalmente el comprador disminuye el valor del artículo para lograr que el vendedor acceda a la rebaja de precio.
} 
Con la estrategia de desvalorización por comparación, el sujeto enunciante muestra al sujeto destinatario que los cocos no tienen un tamaño adecuado, haciéndole ver desde el principio del diálogo que no pagará un alto precio por el producto, y podemos ver que desde esta intervención de inicio la compradora da comienzo al duelo de regateo.

Así, luego de escuchar el costo, el Yo comunicante (el sujeto de la realidad) observa los cocos de menor precio. Entonces, el Yo enunciante (el sujeto discursivo que expresa su intencionalidad) realiza una afirmación sobre la cantidad de dinero que posee: "tengo 1.500", y con esta afirmación establece el costo del artículo sin darle oportunidad al vendedor de objetar la función que ella se ha atribuido. Si el enunciado se expresara en forma de pregunta como: “'me lo puede vender en 1.500?”, sería una petición que da la posibilidad al vendedor de aceptarlo o no, pero el propósito es fijar definitivamente el precio.

El sujeto interpretante, al interpretar la expresión del Yo enunciante, rechaza su propuesta y no corresponde con el tú destinario que el Yo enunciante había idealizado. En el momento de la transacción, el vendedor no accede al precio fijado por la compradora. Ésta, como sujeto enunciante, reacciona alterada y reclama que su propuesta no haya sido aceptada.

En el último intercambio (Briz, 1998: 54), el vendedor, quien es ahora el sujeto enunciante, expresa: "i¿Tú qué crees, que eres la que mandas aquí?!", manifestándole al sujeto destinatario, que como dueño de la colmena es él quien da precio a los artículos. Esto es, el posicionamiento como dueño del establecimiento. Pero el Tú destinatario, como intervención final, hace uso de la amenaza de no realización de la compra, como una forma de posicionarse como compradora, pues si ella decide no comprar el producto, ninguna de las dos partes obtendrá beneficio alguno. A pesar de esto, en la interacción sale ganando el vendedor, pues vende los cocos al precio que dijo en un principio.

\section{b. "Te pones la corbata"}
C: ¿Plátano maduro tienes ahí?
$V$ : Sí, ve'los ahí
C: Nombe $^{10}$, están duros (la señora se va)

\footnotetext{
10 "Nombe" es una expresión de rechazo, muy popular en el habla costeña. Puede entenderse como una contracción de la expresión "no, hombre". Ésta última es un vocativo usado mayormente como llamado de atención: "iQue no coja eso, hombre!".
} 
$V$ : ¡Qué duros! ¡Ven acá, ven acá! (sale del puesto y hace un gesto con la mano en señal de que regrese. La señora vuelve). Míralos, están maduritos, mira este... este (muestra los plátanos)

C: Están es agua'os

$V$ : ¡Viste! Ahora que agua’os

$C$ : (La señora los mira) Están podridos

$V$ : Nombe

C: ¿A cómo estos tres plátanos? (coge tres)

$V$ : Dame mil, ya

$C$ : ¡Qué mil!

$V:$ ¡Ay si son a 400 !

C: Carajo... bueno, dame dos

$V$ : Llévatelos en 700

C: Te pones la corbata

$V$ : ¡Qué corbata! (la señora se va).

Como en el diálogo anterior, éste inicia con la pregunta por el artículo requerido. Inmediatamente, la compradora, como sujeto enunciante, hace uso de la estrategia de desvalorización del producto, pero no compara éste con ningún otro, como en el caso anterior, sino que señala defectos por los cuales no está dispuesta a negociarlo.

De esta interacción, resulta curioso todo lo que hace el vendedor para lograr vender los plátanos, pues trata de convencer a la compradora de que su producto no es como ella lo indica: sale de su región para atraer a la vendedora, le grita para que regrese y observe mejor los artículos, los muestra uno por uno y utiliza la estrategia discursiva opuesta: la valorización del producto. Cuando expresa: "están maduritos"11, enseña a su compradora los méritos que hacen del producto solicitado el mejor. De esta forma busca convencer a la compradora, no sólo de que lleve el producto, sino de que va a adquirir uno de buena calidad. Aun así, ésta insiste en resaltar defectos para lograr que el vendedor le venda los plátanos a un bajo precio.

Es notable el uso de construcciones eco en la interacción. En éstas, el vendedor repite, de forma exclamativa, lo dicho por la compradora: "iqué duros!", para oponerse a la opinión de la compradora; o afirma: "ahora que agua'os". Su estrategia busca contradecir los defectos que destaca la compradora. En otras palabras, el duelo verbal consiste en discutir la calidad del producto, pero ninguno de los sujetos enunciantes quiere ceder a las intenciones del otro: si el uno

${ }^{11}$ En esta ocasión, el uso del diminutivo no indica que la condición de maduros no está dada del todo, es decir, no se usa en forma de atenuación, sino con el propósito de intensificar el carácter de madurez de los plátanos. En el habla costeña es muy usual el uso de diminutivos como forma de intensificación. 
dice un defecto, el otro lo niega destacando una propiedad ("están maduritos") o simplemente, negando en construcción eco. Al final, es el vendedor quien obtiene que su sujeto destinatario desista de su intención y acepte la suya, pues logra que ella decida preguntar por el costo de tres plátanos.

Después de esta pregunta hecha por la compradora, surge, sin embargo, otra estrategia por parte del vendedor: la rebaja de precio antes de que el comprador la exija. El sujeto enunciante afirma: "dame mil, ya"12, como una forma de invitar al sujeto interpretante a no discutir más, sino a que esa sea la solución de la disputa, porque considera que es un precio razonable. No obstante, para el comprador no es así y exclama en construcción eco: “iqué mill!. El vendedor, luego, le hace ver que sí hizo una rebaja, diciendo el precio de la unidad.

En últimas, el sujeto destinatario que el vendedor, como sujeto enunciante, idealizó, se cumple a cabalidad, pues la compradora con resignación y después de tomarse una pausa para pensarlo, acepta el precio del vendedor. Después de haber perdido el duelo, sólo le resta decir, "te pones la corbata", metáfora con la que le expresa al vendedor que sus productos son caros. Otra construcción eco, en muestra de desacuerdo, finaliza el diálogo: “iqué corbata!”.

\section{c. “...bien despacha'o"}
C: Véndeme 500 pesos de cebollín (el vendedor coge la verdura y quita algunas partes). No, pero eso no, no le quites eso (agarra la mano del vendedor que sostiene la verdura). Véndeme 500 pesos de cebollín bien despacha'o
$V$ : Pero es que está a 3.000 el cebollín
$C$ : No, véndeme 500 pesos de cebollín bien despacha'o (suelta la mano del vendedor. Éste accede)

A diferencia de las otras situaciones, ésta no comienza con la pregunta por el precio del producto. Tal vez con el fin de que sea una transacción rápida, el comprador sólo pide el producto y la cantidad que necesita. No hay, sin embargo, una aclaración de la medida que

\footnotetext{
${ }^{12}$ En este caso, el adverbio " $y a$ " no se usa para mostrar inmediatez. En el habla costeña es usado como signo de aprobación o acuerdo, como "listo" o "todo bien". También es una fórmula de despedida: "-Nos vemos en la fiesta -Ya”.
} 
realmente se requiere, como sucede en otros casos que el comprador le exige al vendedor: "échame bastante". Aunque esto no asegura que el vendedor realmente dé más cantidad del producto, es una petición que puede lograr persuadirlo. Pero el vendedor entrega lo que él considera como 500 pesos. Entonces, las opiniones de los participantes discrepan y empieza el duelo.

En primer lugar, el comprador realiza una muestra de insatisfacción por cantidad, al exigir al vendedor que no le quite ninguna parte al producto: "no, pero eso no, no le quites eso". Al agarrar la mano del vendedor, reafirma su petición, pues no la suelta hasta que el vendedor decide hacer lo que, prácticamente, le ha ordenado ${ }^{13}$. El enunciado: "véndeme 500 pesos de cebollín bien despacha'o", expresa de forma más clara su inconformidad, ya que quiere decir que le está vendiendo "mal" la verdura. El duelo es, entonces, por la cantidad de cebollín que se considera justa, por el precio de 500 pesos. Para el comprador, el precio justifica más cantidad de la dada por el vendedor. Éste, dispuesto a no ceder, dice en respuesta el precio por el cual compró el cebollín antes de venderlo en el Mercado de Santa Rita. Esta es la estrategia discursiva de posicionamiento del vendedor como comprador.

Ya hemos dicho que los comerciantes del mercado revenden los productos que consiguen en el Mercado de Bazurto, y ésta es una estrategia que les permite convencer a los compradores del porqué no pueden admitir los precios propuestos. Para este comprador, sin embargo, no es una razón suficiente. Él sólo lucha por su beneficio y con la repetición del enunciado: "véndeme 500 pesos de cebollín bien despacha'o" (junto con el contacto físico que los participantes mantienen durante el diálogo), logra que, finalmente, el vendedor se rinda. Podemos así ver que para el sujeto enunciante la repetición es una forma de enfatizar su propósito, pero sobre todo, de exigirle al sujeto destinatario que cumpla con su intención. En este caso, ganar más por menos.

\section{d. "Esto es un súper aguacate"}

C: ¿A cómo tienes el aguacate? (cogiendo el producto). Ya eso bajó

V: Sí, ya bajó, a 2.500 y a 1.500 (la compradora lo observa fijamente demostrando no creerle). Sií, ya bajó hace raato. Pero,

\footnotetext{
${ }^{13}$ Esto demuestra que en el regateo la relación entre comprador y vendedor es funcionalmente igual, pues al primero no le importa que el vendedor esté detrás del mostrador y al agarrarle la mano por encima de esta barrera se involucra en su región.
} 
mira, están maduritos, esto es un súper

aguacate, un súper aguacate

(La señora no lleva el producto)

En este diálogo, la intervención de inicio de la compradora no sólo es la pregunta por el costo del artículo, sino que, además, va acompañada del enunciado: "ya eso bajó", como una afirmación de la baja de precio del producto. Con esta estrategia, el sujeto enunciante no pide la rebaja, simplemente la insinúa y así se asegura, desde un principio, de que el sujeto destinatario le venda el producto más barato. Pero el sujeto interpretante no corresponde con el sujeto destinatario idealizado por el yo enunciante, pues, aunque afirma que el precio del aguacate bajó, los costos no son los que se imaginaba la compradora. El silencio de ésta y su mirada escéptica le demuestran al vendedor que no cree en los supuestos bajos precios, y dicho silencio indica su oposición y rechazo.

Al vendedor sólo le queda la estrategia de repetición para enfatizar lo dicho: "sií, ya bajó hace raato". Además, es notable un alargamiento vocálico que resalta la afirmación ("Sii") y después intensifica el tiempo que se asume ha transcurrido desde que el precio del aguacate bajó ("hace raato"). Él es consciente, sin embargo, de que los precios son altos. Por eso recurre a la valorización del producto para convencer a la compradora.

En el enunciado: "pero, mira, están maduritos", el uso del conector de contraste: "pero", reafirma lo costoso del producto, ya que el sujeto enunciante invita a su sujeto interpretante a mirar las propiedades del artículo, a pesar del alto precio que tienen. Como en el segundo caso analizado, en éste se valorizan los aguacates por la condición de "maduritos", pues el diminutivo intensifica la propiedad del producto, mas no lo reduce. Incluso se valoriza el producto como el mejor, con un prefijo intensificador: es un "súper aguacate" y una construcción eco reitera esta característica. No obstante, el sujeto interpretante no accede al propósito del Yo enunciante.

\section{e. “¿No me das dos por $500 ? ”$}

Cuando un sujeto enunciante realmente quiere llevar a cabo una intención y lograr un beneficio, recurre a las estrategias que sean necesarias, como en esta situación:

C: ¿A cómo son las mazorquitas?

$V$ : A 300 pesitos 
C: Ignacio, ¿no me das 2 por 500 aaa?, ¿no me das dos por 500 ?

$V$ : Nada, es que son 600 porque después no gano

C: Bueno, coge los 500, ahora que vuelva a comprar el arroz te doy los 100 (la señora guarda los maíces en la bolsa sin dejarle opción al vendedor de impedírselo).

El Yo enunciante hace uso del diminutivo en la intervención de inicio para insinuarle al sujeto interpretante que si las mazorcas son pequeñas, así debe ser su precio. El Yo interpretante entra en el juego del sujeto enunciante y afirma: “a 300 pesitos”, para ratificar que es un precio pequeño que corresponde con las "mazorquitas" mencionadas por el Yo enunciante. Al parecer, como esta estrategia no sirvió, pues el precio no lo consideró adecuado, el Yo enunciante decide preguntar directamente, utilizando la estrategia de lo más por menos que se expresa en enunciados de este tipo: “'no me das dos por 500?"; y a través de la construcción eco y el alargamiento vocálico (“...aaa?") se le insiste en la solicitud. Pero el sujeto interpretante no accede a la petición $\mathrm{y}$, como sujeto enunciante, se posiciona como comprador. Si vende las mazorcas al precio requerido por la compradora, no va a sacar ganancia del costo por el que las pagó en el mercado de Bazurto.

La compradora no se rinde y nuevamente, como sujeto enunciante, hace uso de una estrategia más: compromiso de dar el dinero restante. El vendedor no tiene forma de rehusarse y con un silencio acepta la propuesta de la compradora. Finalmente, se convierte en el sujeto destinatario idealizado por este Yo enunciante, que no dejaría de usar estrategias hasta conseguir su objetivo.

\section{f. “¡Tres mil seis!”}

(En una venta de pollo)

$C$ : ¡Tres mil seis! ¡Tres mil seis!

$V$ : Tres mil setecientos vale

$C$ : Tres mil seis pa' comprártelo ya, siempre que vengo lo compro a tres mil seis

$V$ : Será en...

$C$ : ¡Tres mil seis!

$V$ : Será en tus sueños que lo compraste a tres mil seis

$C$ : Tres mil seis mi hermano (El comprador lleva el producto al precio que exigía) 
Aunque no sabemos cómo empezó este duelo, nos pareció importante analizarlo por diversos aspectos. En primer lugar, nos llamó la atención que en el momento en el que se desarrollaba la discusión todas las personas alrededor observaban lo que pasaba, pues el comprador alzaba bastante la voz, casi que gritaba y todos creíamos que peleaba con el vendedor. Después nos percatamos de que la disputa giraba en torno al precio de un salchichón.

Podemos ver que el comprador grita el precio por el que desea comprar el producto, pero el vendedor está reacio a despacharlo a ese precio e insiste en un costo más alto. La estrategia del comprador es la repetición, por medio de la cual persiste en su petición y la enfatiza: "Tres mil seis". Además, consideramos que el comprador hace uso de la amenaza de no realización de la compra, cuando afirma: "Tres mil seis pa comprártelo ya". Con esta expresión le da a entender al vendedor que si no le vende el producto al precio solicitado, no realizará la compra, y así, ni él, como comprador, ni el vendedor, obtendrán alguna ganancia. De la sugerencia pasa, sin embargo, a la reclamación y utiliza la estrategia de afirmación de compras anteriores con el mismo precio. A través de ésta, le exige al vendedor que le despache el producto al precio que siempre lo ha conseguido en el establecimiento: "siempre que vengo lo compro a tres mil seis".

Otra razón por la que decidimos analizar este duelo, a pesar de no haberlo observado desde el inicio, es la forma burlona cómo el vendedor se rehúsa a vender el producto al precio exigido por el comprador. Después de una interrupción por parte de este último, que intenta arrebatarle el turno (Briz, 1998: 52), el vendedor retoma su intervención y expresa: "Será en tus sueños que lo compraste a tres mil seis". Como indicamos al inicio de este capítulo, las situaciones de regateo se caracterizan por el humor que los participantes le imprimen a sus intervenciones. En este caso, el vendedor hiperboliza la afirmación del comprador, hasta el punto de ridiculizarlo con el fin de hacerle ver que el precio que reclama es una invención, como lo es también el hecho de que haya adquirido, en ese establecimiento, el producto con dicho precio.

Al final el comprador, como sujeto enunciante, gana el duelo debido a su persistencia, a su afán de llevar el producto al precio exigido. La estrategia de repetición logra que el sujeto destinatario acceda al precio propuesto por el comprador. 


\title{
g. "Dame los cinco por mil"
}

\author{
C: ¿Estos cuatro plátanos? \\ $V$ : Son mil \\ C: ¿¿Qué mil?! ¿No son a 200? \\ $V$ : No, son mil \\ C: Dame los cinco por mil (lleva el producto)
}

En la fachada (Goffman, 2004: 34) de este establecimiento, el vendedor tiene ubicada por fuera de las paredes del puesto una mesa en la que, de acuerdo al producto que esté en cosecha, organiza unas pilas que pueden ser de plátanos, de aguacates, de mangos, etc. En esta situación, el vendedor ha organizado unas pilas de cuatro plátanos y el comprador, al llegar al puesto, pregunta por una de ellas. Sin embargo, al escuchar el precio dado por el vendedor, el sujeto enunciante expresa su admiración a través de una construcción eco en forma exclamativa: “iQué mil?!”. Construcción que complementa con la estrategia de afirmación de compras anteriores con el precio de rebaja: “¿no son a 200?”. Aunque el yo enunciante no diga explícitamente que en ese establecimiento ha comprado los plátanos al menor precio, sí le recuerda al sujeto interpretante que ese es el precio al que habitualmente consigue dicho producto.

El sujeto interpretante, ahora enunciante, con sólo repetir el precio ya estipulado busca que el Tú interpretante entienda que el costo que exige no es el adecuado. No obstante, el comprador, como sujeto enunciante, no se rinde y hace uso de otra estrategia: lo más por menos, exigiéndole al vendedor más unidades del producto al mismo precio. De esta forma, el cliente asegura al comerciante una venta, y a la vez, gana el duelo adquiriendo a un menor costo el artículo que deseaba.

Este pequeño duelo verbal, responde a la estructura típica del regateo: un comprador pregunta por el precio de un producto, el vendedor da un precio que no se acomoda a las expectativas del comprador; éste reacciona, exigiendo un costo más barato, pero el vendedor se opone. El comprador hace una propuesta al vendedor para que éste acepte vender el producto y, finalmente, si la propuesta le conviene, el vendedor accede.

\section{h. “'Tan malucos esos tomates?”}
C: ¿Y esos tomates Álvaro?
$V:$ A 200
C: ¿Tan malucos esos tomates? 
V: Sí, a 200, a 200

C: Erda $^{14}$, Álvaro, a 200 esos tomates tan feos y esos tomates no bajan. Voy al mercado y los consigo más baratos (no lleva el producto)

Al igual que en la situación anterior, podemos observar un duelo típico en el cual el cliente reacciona impresionado al precio dado por el vendedor, para así empezar la negociación. Pero, en este caso, a la compradora no le parece adecuado el costo del producto, por la condición en el que éste se encuentra, y lo desvaloriza: “ ¿Tan malucos esos tomates?”. El vendedor sólo repite el precio para confirmar su aseveración, aunque la compradora, como sujeto enunciante, considera que al desvalorizar el producto el sujeto destinatario rebajará el precio.

Como esto no es suficiente, el Yo enunciante reutiliza la estrategia de desvalorización del producto ("a 200 esos tomates tan feos"), realiza una afirmación del alza del precio del mismo (" $y$ esos tomates no bajan"), y por último, recurre a la estrategia de referencia de otro lugar de compra, cuando expresa: "voy al mercado y los consigo más baratos". No obstante, esta referencia no convence al sujeto interpretante, de manera que no se convierte en el tú destinatario que el sujeto enunciante había idealizado.

\section{i. “YY sacó la que más tenía, ira!”}
C: ¿A cómo la maracuyá?
V: 3.200
C: ¿Mil?
V. ¡3200! (alza la voz). 3.200 para usted
$C$ : (La señora introduce en una bolsa las maracuyás que quiere comprar y se la da al vendedor). Pesa completo, porque está muy cara y no vas a sacar
(El señor pesa y saca una maracuyá. La señora la coge)
$C$ : ¡Y sacó la que más tenía, ira ${ }^{15}$ !
$V$ : Páseme una pequeñita (pesa y le da la bolsa. La señora lleva el producto).

Este diálogo comienza de manera peculiar, pues la compradora es una anciana y como la primera vez no escuchó el precio correcto,

\footnotetext{
${ }^{14}$ La palabra "erda" podemos entenderla como una contracción eufemística de la expresión "mierda", que expresa rechazo, decepción o resignación.

${ }^{15}$ La expresión "ira", puede ser tomada como una contracción de la palabra "mira", que en algunos casos constituye un llamado de atención. Vale aclarar que es usada en forma exclamativa la mayoría de las veces.
} 
cree que el kilo de maracuyá vale mil pesos, pero el vendedor corrige inmediatamente, gritándole el precio real, y para que la compradora continúe creyendo que es un bajo precio, como el que escuchó inicialmente, hace uso de la estrategia de rebaja de precio antes de que el comprador la exija, al afirmar: "3.200 para usted". De esta forma, el sujeto enunciante muestra cierta exclusividad con el sujeto interpretante, para que compre el producto al precio, supuestamente especial.

A pesar de esto, el sujeto interpretante exige al vendedor una buena cantidad del producto, porque se percata de que el costo es elevado. Precisamente, como sujeto enunciante, hace una afirmación del alza del precio del producto y a la vez exige una buena cantidad, porque va a pagar el precio establecido: "pesa completo porque está muy cara y no vas a sacar". El vendedor, no obstante, ignora la petición de la compradora y saca una de las maracuyás seleccionadas. La compradora toma la maracuyá, la agita para escuchar la pulpa y usa la estrategia de muestra de insatisfacción por cantidad cuando exclama: “YY sacó la que más tenía, ira!”, para manifestarle al vendedor su rechazo ante la medida que despachó. En últimas, el vendedor gana el duelo, pues vendió el producto al precio que estipuló desde un inicio y no aceptó la petición de la compradora en cuanto a la cantidad que vendía.

\title{
j. “¿...a cómo me la va a dejar?
}

\author{
C: ¿Y esa papaya a cómo me la va a dejar? \\ V: A 1.500 \\ C: ¿Qué? \\ V: 1.500 \\ C: Está cara \\ $V$ : Nombe, está barata, está en promoción \\ C: Está cara. (Después de pensarlo) Dámela pues
}

En contraste con el duelo de regateo típico, en el cual siempre se discute el precio después de haber sido preguntado, el presente diálogo no da cabida a un primer precio, pues desde su inicio el comprador indaga por el precio más barato con la estrategia de pregunta inmediata del precio de rebaja: "¿y esa papaya a cómo me la va a dejar?". Con esta estrategia el sujeto enunciante idealiza un sujeto destinatario que responde a dicha pregunta con un costo del producto más económico del habitual. El sujeto interpretante, sin embargo, no corresponde con ese tú destinatario y da un precio, según el cliente, muy elevado. Así lo deja ver este último cuando realiza una afirmación del alza de precio del producto: "Está cara". 
De hecho, el comprador vuelve a preguntar el precio del producto, porque no lo considera realmente rebajado, y el vendedor repite el mismo costo para hacerle ver al comprador que ese es el precio de rebaja solicitado, aunque tal vez no sea así. Además, el comerciante también hace uso de la estrategia de afirmación del bajo costo del producto para contradecir la aseveración del cliente: "Nombe está barata, está en promoción". A pesar de no estar convencido del todo y repetir que la papaya "está cara", el comprador acepta el precio establecido por el vendedor. Quizá, desde el principio sí lo consideró un costo aceptable, pero con tal de obtener el producto más barato, utilizó las estrategias mencionadas. Como hemos dicho, se regatea para alcanzar el máximo beneficio. En el caso del comprador, el precio lo más rebajado posible.

\section{k. "pa' qué la vamos a engañar".}
C: ¿El aguacate a cómo?
V: A 1.000 y a 1.500
$C$ : Pero ese tiene la punta fea
$V$ : Pero por dentro están bonitos doña, ¿se lo parto?
C: Pártelo.
$V$ : (El vendedor divide el aguacate por la mitad) Mire qué bonito
$C$ : Y ese, ese tiene un golpe
$V$ : No, doña, eso usted se lo quita con el cuchillo. Mire que está bonito por dentro (lo parte), pa' qué la vamos a engañar
C: Bueno, dame esos dos

La estrategia discursiva de desvalorización del producto usada por los compradores tiene una estrategia que la contradice directamente y es la valorización del producto, utilizada por los vendedores. En este diálogo, por ejemplo, el duelo se concentra en el buen o mal estado del producto, y por tanto, los participantes discuten que el precio corresponda a las características del artículo. Entonces, la compradora insiste en sacar a flote los defectos (desvalorización) para obtener un precio más bajo y el vendedor trata de destacar las propiedades (valorización) para poder justificar el costo establecido.

"Pero ese tiene la punta fea", "y ese, ese tiene un golpe", son las expresiones usadas por la compradora como Yoe para desvalorizar los aguacates y lograr un precio más bajo. Por su parte, el vendedor, como Yoe, repite la misma expresión en formas sutilmente distintas: "Pero por dentro están bonitos, doña", "mire qué bonito", "mire que está bonito por dentro". El vendedor, con tal de hacer la venta, abre los dos aguacates para que la compradora los vea en su interior. Es decir, 
unido a las estrategias discursivas, también está el contacto con el producto: observarlo, tocarlo. De ahí que los compradores puedan seleccionar los productos que quieren adquirir, pues es también ésta una estrategia de venta, aunque no discursiva.

Cabe destacar que en últimas, las dos partes involucradas logran persuadirse mutuamente a través de estrategias, ya que el vendedor, al final del diálogo, acepta el defecto del aguacate señalado por la compradora, "el golpe". Pero, a la vez, la convence de que es un defecto que puede eliminarse con facilidad y que, a pesar de él, el aguacate permanece intacto en su interior. Así mismo sucede al inicio del duelo: el vendedor sabe que el aguacate tiene "la punta fea". Por eso muestra el interior del producto, para que la compradora acceda a llevarlo, como sucede efectivamente. Podríamos decir entonces que el vendedor logró la venta por su sinceridad ("pa que la vamos a engañar"), al admitir las imperfecciones de sus productos, pero también, por no olvidar la promoción de los mismos, valorizando sus mejores características.

\title{
l. "Ay, si quieres hacer unos bolis"
}

\author{
C: ¿A cómo el aguacate? \\ V: A mil \\ C: ¿Todo a mil? \\ V: Todo a mil, mi reina. Hasta la concha, mira, está bonita \\ C: Ajá, ¿y yo que voy a hacer con la concha, según tú? \\ $\mathrm{V}$ : Ay, si quieres hacer unos bolis. \\ C: (Risas) (La señora lleva el producto)
}

Este diálogo es una excepción entre todas las situacionesya analizadas, pues la compradora, al escuchar el precio dado por el vendedor, en vez de regatear por un precio más bajo, se sorprende de que el costo esté rebajado. Al parecer, el vendedor hizo uso de la estrategia de rebaja de precio antes de que el comprador la exija. A través de una construcción eco, la clienta pregunta, admirada: “'todo a mil?”. El vendedor responde afirmativamente por medio de otra construcción eco, y como sujeto enunciante, aprovecha para valorizar el producto, destacando su exterior: la concha. La compradora se percata de que es exagerada la aseveración del vendedor ("hasta la concha, mira, está bonita"). Como una forma de seguir su juego burlesco, pregunta por la utilidad de esa concha. El vendedor hiperboliza todavía más su respuesta, cuando expresa: "ay, si quieres hacer unos bolis". La valorización, entonces, se convierte en un motivo de jocosidad para el vendedor y así obtiene que la compradora lleve el producto, además de que pudo piropear a la dama y hacerla reír. 


\section{A modo de conclusión}

El uso de estrategias discursivas en diálogos cotidianos, como el duelo verbal de regateo, es una muestra de que con la lengua interactuamos con el otro, especialmente para persuadirlo de acceder a nuestros propósitos. Es decir, verbalmente podemos convencer a nuestros interlocutores de cumplir o realizar determinadas acciones que nos beneficien en cualquier circunstancia. En este sentido, las estrategias discursivas no son más que herramientas comunicativas o mecanismos que le permiten a un hablante lograr un cierto objetivo, como por ejemplo (para un comprador) conseguir la rebaja de precio de un producto en un local comercial. En el regateo, sin embargo, el vendedor también tiene una intención: mantener el precio que asignó al producto desde un principio. Por esto el regateo es un duelo verbal, donde cada participante quiere alcanzar un fin y para esto se disputa verbalmente a través de dichas estrategias.

El regateo tiene cabida, sobre todo, en lugares como las plazas de mercado, ya que en ellas se manifiesta una relación de proximidad entre compradores y vendedores. De tal forma que el Mercado de Santa Rita constituye un lugar de encuentro para todas las comunidades cercanas, porque hay más posibilidad de diálogo y, por tanto, de expresar desacuerdo o inconformidad. En este sentido, podemos ver el regateo como una práctica cultural que está arraigada en el carácter conversador de los compradores y vendedores de esta plaza de mercado, quienes, además, comparten similares necesidades económicas y sociales, y el regateo es una manera de sobrellevar tales carencias.

Por último, tal vez no sea exagerado decir que, si pensamos en que negociar es concertar, poner en conflicto opiniones y discutir beneficios, el regateo, como práctica comercial, es una verdadera negociación en la cual tanto comprador como vendedor realmente debaten los beneficios que quieren alcanzar, y al final, los dos obtienen alguna ganancia. Pero siempre uno de los participantes saca más provecho de dicha negociación (es decir, resulta vencedor), pues es quien logra convencer al otro por medio de las estrategias discursivas adecuadas.

El regateo puede ser visto entonces en tres aspectos: 1) como una práctica comercial, porque tiene lugar en la actividad transaccional; 2) como una práctica cultural, porque surge en consonancia con ciertas características sociales de la comunidad; y 3) como un duelo verbal, porque es una disputa por alcanzar unos propósitos (una disputa netamente discursiva) y que se vale de determinadas estrategias para que dichos propósitos se cumplan. 


\section{Bibliografía}

Benveniste, E. (1979). Problemas de lingüística general II. México: Siglo XXI Editores.

Beuchot, M. (2004). La semiótica. México: Fondo de Cultura Económica. Briz, A. (1998). El español coloquial en la conversación. Barcelona: Ariel.

Charaudeau, P. (1983). Langage et discours. Eléments de sémiolinguistique (Théorie et practique). Paris: Hachette.

Corominas, J. \& Pascual, J. (1981) Diccionario crítico etimológico castellano e hispánico. Madrid: Gredos, vol. IV.

Escamilla, J. (1998). Fundamentos semiolingüísticos de la actividad discursiva. Bogotá: Universidad del Atlántico.

Goffman, E. (2004). La presentación de la persona en la vida cotidiana. Buenos Aires: Amorrortu.

Martínez Cortiña, R. (Dir.). (1980) Economía. Diccionario Enciclopédico. Barcelona: Planeta.

Ogliastri, E. (2001). Cómo negocian los colombianos. Colombia: Alfaomega, vol. III.

Seldon, A. \& Pennance, F.G. (1975). Diccionario de economía. Una exposición alfabética de conceptos económicos y su aplicación. Barcelona: Oikos-tau.

Sherzer, J. (2000). "Lengua y cultura enfocadas en el discurso”. En Lastra, Y. (Comp). Estudios de sociolingüística. México: Instituto de Investigaciones Antropológicas, Universidad Nacional, Autónoma de México, pp. 515-541.

Tabares, R. \& Arias, J. (2008). “La práctica del regateo como expresión de una tradición comercial en los centros comerciales San Andresito y el centro Galerías Plaza del mercado de la ciudad de Manizales". En Pindado García, G. (Comp.), Establenciendo puentes en una economía global, vol. II, en http://dialnet.unirioja.es/servlet/ articulo?codigo $=2739163$

Vizcaíno, A. (2008). Manual del perfecto regateador", en http://www.scribd. com/doc/6542031/Manual-Del-Perfecto-or 
